\title{
Ventromedial Hypothalamic Lesions and the Mobilization of Fatty Acids
}

\author{
Yoshiki Nishizawa and George A. Bray, Department of Medicine, \\ University of California, Los Angeles School of Medicine, Harbor General \\ Hospital Campus, Torrance, California 90509
}

\begin{abstract}
A B S TRACT We have explored the effects of ventromedial hypothalamic lesions on the mobilization of free fatty acids in rats exposed to several stresses. The rise in free fatty acids and glycerol in response to norepinephrine had the same time-course and doseresponse characteristics in the sham-operated and lesioned animals, indicating comparable degrees of peripheral responsiveness to this hormone. Forced swimming significantly lowered insulin and increased glycerol and free fatty acids more in control than in ventromedial hypothalamic-lesioned rats. During fasting, the rise in glycerol and free fatty acids was smaller in the lesioned rats, but the fall in insulin was greater. Exposure to cold raised fatty acids and glycerol more in the control than in the sham-operated animals, but had no significant effect on plasma insulin or glucose concentration. Injection of 2-deoxyglucose was done on lesioned or control rats with intact or removed adrenal medullas. The rise in free fatty acids and glycerol was less in the lesioned rats than in the controls, and was not affected by adrenodemedullation. The rise in glucose, however, was completely blocked in the adrenodemedullated rats. Changes in insulin were small and not statistically significant. The reduced mobilization of fatty acids from adipose tissue depots after ventromedial hypothalamic injury is consistent with the hypothesis that the ventromedial hypothalamic region serves to modulate activation of the sympathetic nervous system.
\end{abstract}

\section{INTRODUCTION}

Several experimental models of obesity have been used in the search for increased understanding of the syndromes of human obesity. These models include the obesity that is genetically transmitted $(1,2)$, the obesity that follows dietary manipulations (3), the obesity that results from alterations in endocrine function (2), and

Received for publication 7 February 1977 and in revised form 26 October 1977. obese animals with bilateral ventromedial hypothalamic lesions (4).

This latter syndrome of hypothalamic obesity results from destruction of the ventromedial region of the hypothalamus in both man (5) and animals (4). The pathologic lesions that have been associated with this syndrome in human beings include tumors, inflammatory lesions, trauma, and congenital malformations (5). Like its experimental counterpart, this syndrome in man is associated with an initial period of weight gain followed by a plateau in body weight. Most of the increase in body weight can be accounted for by an increase in the size of pre-existing fat cells (5). Hyperphagia, hypometabolism, and abnormalities of endocrine function are frequent features of both the human and experimental syndromes $(4,5)$.

The region of the hypothalamus whose injury produces this syndrome sits astride the fibers of the sympathetic nervous system (6-8) and, thus, suggests the possibility that it may modulate the function of the adrenergic nervous system. Diminished activity of the sympathetic nervous system might be involved in the hyperinsulinemia characteristic of this syndrome in both animals and man $(4,5)$. Reduced sympathetic activity might also account for the lower concentrations of glucagon and the smaller salivary glands that have been reported to follow ventromedial hypothalamic injury and obesity in experimental animals (9). The present experiments were designed to examine the effects of ventromedial hypothalamic injury in experimental animals using mobilization of fatty acids from adipose tissue as an index of activation of the sympathetic nervous system.

\section{METHODS}

\section{Animals}

The 336 female Wistar rats used for these studies were obtained from Simonsen Laboratories, Gilroy, Calif., and weighed between 240 and $280 \mathrm{~g}$. They were fed pelleted or 


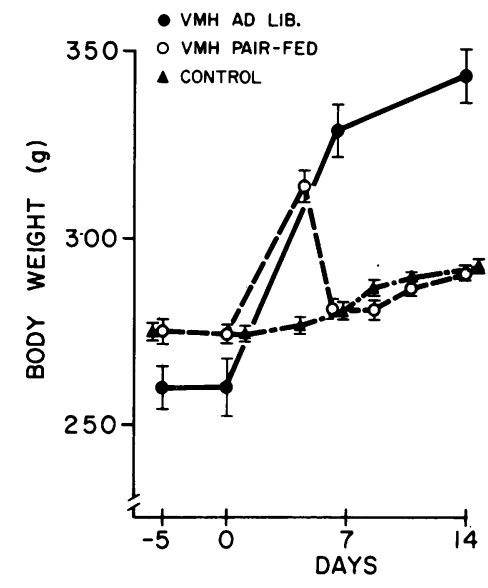

Figure 1. Change in body weight for ad lib. and pair-fed animals. After a VMH lesion, both groups of animals gained weight rapidly. After the 5 th day, food intake was restricted in one group ( $\left.\mathrm{O}_{--} \mathrm{O}\right)$ for 2 days, and these animals were then pair-fed to maintain body weights the same as in the sham-operated controls.

ground Purina Laboratory Chow (Ralston Purina Co., St. Louis, Mo.). Tap water was available ad lib.

\section{Experimental procedures}

Surgical procedures. Ventromedial hypothalamic $(\mathrm{VMH})^{1}$ lesions were produced by constant anodal current of $2 \mathrm{~mA}$ (Stoelting Co., Chicago, Ill.), passed for $20 \mathrm{~s}$ through a stainless steel electrode insulated except for the tip. The coordinates were the bregma anteriorly; $\pm 0.7 \mathrm{~mm}$ from the midline and $1 \mathrm{~mm}$ from the base of the skull (10). Adrenodemedullation was carried out through bilateral flank incisions under ether anesthesia by nicking the capsule of the adrenal gland and squeezing out the adrenal. Confirmation of completeness of demedullation was verified at autopsy by slicing the adrenal and checking for medullary tissue. In previous studies, this technique was compared with chemical determination for catecholamines and found to be a good guide to adequacy of adrenodemedullation (11).

General protocol. The general protocol is shown in Fig. 1. After introduction of the hypothalamic lesions, rats were allowed to eat ad lib. for 5 days. Animals gaining weight rapidly during this period were used for the experiment. At the end of this 5-day period, food intake was restricted for 2 days to reduce body weight to the same level as in the sham-operated animals. VMH-lesioned rats were subsequently pair-fed to the intact lean animals until the time of the experiment. On the day before the experiment, the food for the VMH-lesioned rats was divided in half, with half given at $9 \mathrm{a} . \mathrm{m}$. and half at 12 midnight. Rats were not fasted before the experiments.

Exercise. According to the protocol of Federspil et al. (12) vigorous physical exercise was produced by having the rats swim. For this study, animals were adapted to swimming by immersing them in $32^{\circ} \mathrm{C}$ water for $5 \mathrm{~min}$ initially, and then gradually increasing the duration to $10,20,40$, and $60 \mathrm{~min}$ before introducing the hypothalamic lesion. 14 days after introduction of the hypothalamic lesion, the eight rats in each

${ }^{1}$ Abbreviation used in this paper: VMH, ventromedial hypothalamic. group which were fed as described above underwent the final swim for $60 \mathrm{~min}$, after which they were sacrificed.

Cold exposure. Rats were placed in individual stainless steel cages in a cold room at $4^{\circ} \mathrm{C}$ for $60 \mathrm{~min}$ before autopsy. They had been fed up until the time of cold exposure. Each group consisted of seven or eight rats.

Fasting. Food was removed at $8 \mathrm{a} . \mathrm{m}$. from three groups containing eight sham-operated and three groups with a similar number of VMH-lesioned rats. One group with each type of operation was killed when the food was removed; a second pair of groups at 4 p.m.; and the third pair of groups at 8 a.m. the next day.

2-Deoxy-D-glucose. 2-Deoxy-D-glucose (Sigma Chemical Co., St. Louis, Mo.), was dissolved in distilled water and administered intraperitoneally at a dose of $500 \mathrm{mg} / \mathrm{kg}$. Both the adrenodemedullated and sham-demedullated rats had been fed until the time of treatment. They were sacrificed $30 \mathrm{~min}$ later. Each vehicle or treatment group contained 10 rats.

Norepinephrine. 1-Norepinephrine (Winthrop Laboratories, Evanston, Ill.) was dissolved in $0.15 \mathrm{M}$ sodium chloride solution and administered intraperitoneally in doses of $30,100,300$, and $600 \mu \mathrm{g} / \mathrm{kg}$ and for the time-course experiment, in doses of $100 \mu \mathrm{g} / \mathrm{kg}$. Each treatment group for the time-course contained 8 rats, whereas the dose-response study contained 10 rats in each group.

\section{Assays}

Serum glucose was measured by the glucose oxidase method which also measures 2-deoxy-D-glucose (Glucose Analyzer, Beckman Instruments, Inc., Fullerton, Calif.). The addition of 2-deoxy-D-glucose at a concentration of $100 \mu \mathrm{g}$ increased the apparent concentration of glucose by $40 \mathrm{mg} / \mathrm{dl}$. Serum free fatty acids (FFA) were assayed by the method of Dole (13) using 0.5-ml aliquots of serum. Serum glycerol was determined by the glycerol kinase method of Davidson and Karjala (14). Immunoreactive insulin was determined by a double antibody method using rat insulin standards and iodinated pork insulin with an anti-insulin antibody raised in the guinea pig (15).

\section{Statistical treatment}

The data were analyzed by analysis of variance, and results are expressed as the mean \pm SEM. Statistical significance was selected at a level of $P<0.05$.

\section{RESULTS}

\section{Experiment 1}

Time-course of response to norepinephrine. A dose of norepinephrine of $100 \mu \mathrm{g} / \mathrm{kg}$ body weight significantly increased the serum glycerol and FFA in both lesioned and control rats killed 10, 15, and $30 \mathrm{~min}$ after injection $(F=3.35 ; P=0.026$ for rise in FFA) (Fig. 2 ), but there were no significant differences between the groups $(P=0.067)$. Indeed, glycerol rose more and FFA somewhat less in the VMH-lesioned rats. Glucose also rose after injection of norepinephrine (135 \pm 2 to $213 \pm 10 \mathrm{mg} / \mathrm{dl}$ in controls and $133 \pm 4$ to $229 \pm 11 \mathrm{mg} / \mathrm{dl}$ in VMH-lesioned rats), but there were no significant differences between the two groups at any time. Immunoreactive insulin was significantly higher in 


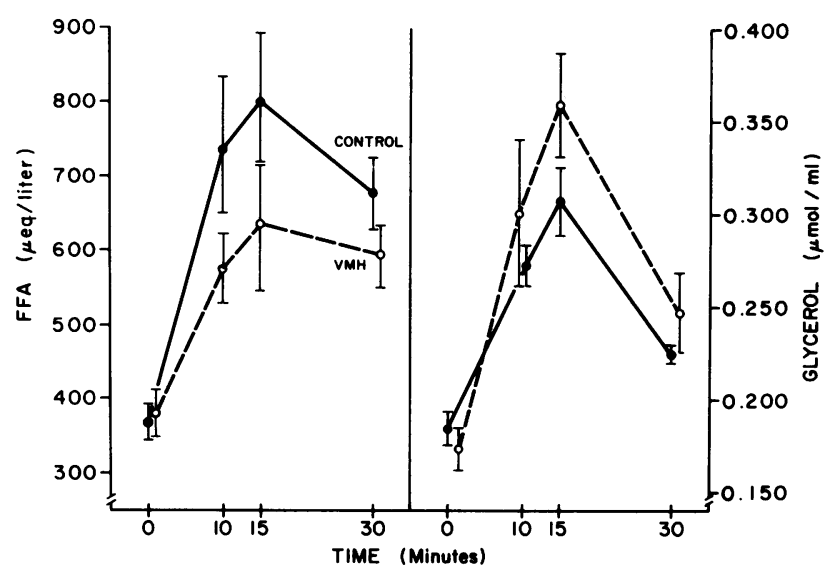

Figure 2. Time-response to norepinephrine. FFA and glycerol were measured in VMH-lesioned and control rats at 10,15 , and $30 \mathrm{~min}$ after injecting $100 \mu \mathrm{g} / \mathrm{kg}$ of norepinephrine. The rise in glycerol was slightly more and the rise in FFA slightly less in the VMH-lesioned rats, but there were no significant differences by analysis of variance.

VMH-lesioned rats $(38.5 \pm 7$ vs. $21.2 \pm 3.4 \mu \mathrm{U} / \mathrm{ml})$, and decreased after injection of norepinephrine (minimum of $6.6 \pm 2.0$ in control and $11.9 \pm 3.9 \mu \mathrm{U} / \mathrm{ml}$ in $\mathrm{VMH}$ lesioned rats). The difference in immunoreactive insulin between the two groups had disappeared at 15 and $30 \mathrm{~min}$ after injecting norepinephrine.

\section{Experiment 2}

Dose response to norepinephrine. A rise in the concentration of glycerol and FFA was observed with all doses of norepinephrine (Fig. 3). By analysis of variance, the rise in FFA was significantly higher in the sham-operated controls $(F=8.24 ; P=0.006)$, but there was no significant difference in the two groups in the rise of glycerol after norepinephrine. Glucose in-

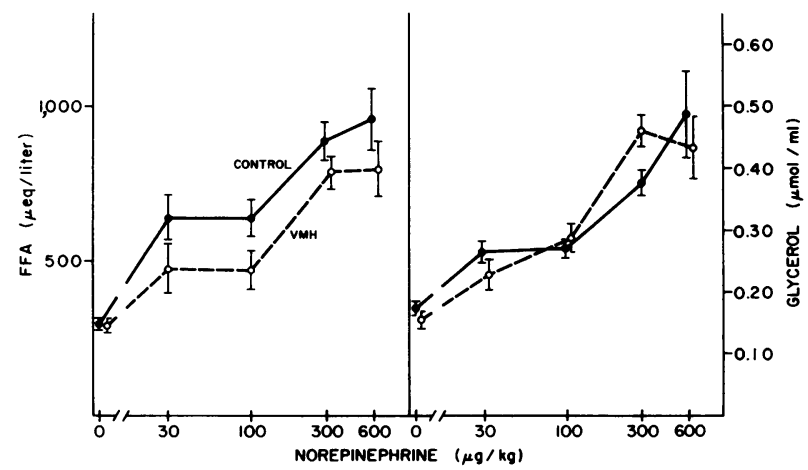

Figure 3. Dose response to norepinephrine. Both glycerol and FFA increased after the injection of all doses of epinephrine. There were no significant differences in glycerol at any time, but the fatty acids were significantly higher in the sham-operated rat. creased similarly in the VMH-lesioned and intact animals after injection of norepinephrine $(135 \pm 3$ to $280 \pm 53 \mathrm{mg} / \mathrm{dl}$ in controls and $133 \pm 4$ to $274 \pm 5 \mathrm{mg} / \mathrm{dl}$ in VMH-lesioned rats). Immunoreactive insulin was higher in the VMH-lesioned groups $(63.5 \pm 14$ vs. $20.5 \pm 4.4 \mu \mathrm{U} / \mathrm{ml}$ ) and decreased in both groups. Significant differences were still present after 30,100 , and $300 \mu \mathrm{g} / \mathrm{kg}$ but not at $600 \mu \mathrm{g} / \mathrm{kg}$ of norepinephrine.

\section{Experiment 3}

Exercise. FFA and glycerol concentrations were the same in the groups of animals that did not exercise. FFA were significantly higher in the control rats which swam for $60 \mathrm{~min}$ when compared to the VMH-lesioned animals which had exercised for the same period of time (Fig. 4). Glycerol concentrations behaved similarly $(0.21 \pm 0.03$ and $0.20 \pm 0.01 \mu \mathrm{mol} / \mathrm{ml}$ in control and $0.59 \pm 0.04$ and $0.47 \pm 0.05 \mu \mathrm{mol} / \mathrm{ml}$ after exercise in control and VMH-lesioned groups, respectively). Glucose also increased in rats that had exercised $(177 \pm 6 \mathrm{mg} / \mathrm{dl}$ in control and $175 \pm 8 \mathrm{mg} / \mathrm{dl}$ in $\mathrm{VMH}$ lesioned animals), but there were no differences in glucose concentration in those animals that exercised and those that did not $(141 \pm 4 \mathrm{mg} / \mathrm{dl}$ in control and $135 \pm 10 \mathrm{mg} / \mathrm{dl}$ in VMH-lesioned rats). The concentrations of insulin were higher in the VMH-lesioned rats that did not exercise $(31.5 \pm 7.0$ vs. $16.6 \pm 4.3 \mu \mathrm{U} / \mathrm{ml})$. The values in the groups that exercised were lower $(2.1 \pm 0.9 \mu \mathrm{U} / \mathrm{ml}$ in control and $7.5 \pm 0.9 \mu \mathrm{U} / \mathrm{ml}$ in $\mathrm{VMH}$ lesioned rats) and significantly different.

\section{Experiment 4}

Exposure to cold. FFA were significantly higher in the animals exposed to cold than in the animals that were not cold stressed (Table I). After exposure to cold, the VMH-lesioned animals had significantly lower concentrations of FFA $(515 \pm 30 \mathrm{vs} .626 \pm 24 \mu \mathrm{eq} / \mathrm{ml})$ and glycerol $(0.29 \pm 0.01$ vs. $0.37 \pm 0.018 \mu \mathrm{mol} / \mathrm{ml})$ than $\mathrm{did}$ the sham-operated animals. Glucose decreased slightly but there was no difference between the lesioned and sham-operated animals $(137 \pm 3$ before, to $126 \pm 4 \mathrm{mg} / \mathrm{dl}$ after cold in control and $135 \pm 3$ before, to $121 \pm 1 \mathrm{mg} / \mathrm{dl}$ after cold in VMH-lesioned rats). The concentration of insulin was higher in the VMH-lesioned animals $(47.9 \pm 13$ vs. $24.3 \pm 2 \mu \mathrm{U} / \mathrm{ml})$, and there was no significant change in insulin after $60 \mathrm{~min}$ of exposure to the cold $(22.5 \pm 3.2 \mu \mathrm{U} / \mathrm{ml}$ in control and $46.7 \pm 6.9 \mu \mathrm{U} / \mathrm{ml}$ in VMH-lesioned rats).

\section{Experiment 5}

Fasting. FFA and glycerol rose after 8 and $24 \mathrm{~h}$ of fasting and were significantly higher in the fasted sham-operated animals than in the VMH-lesioned 

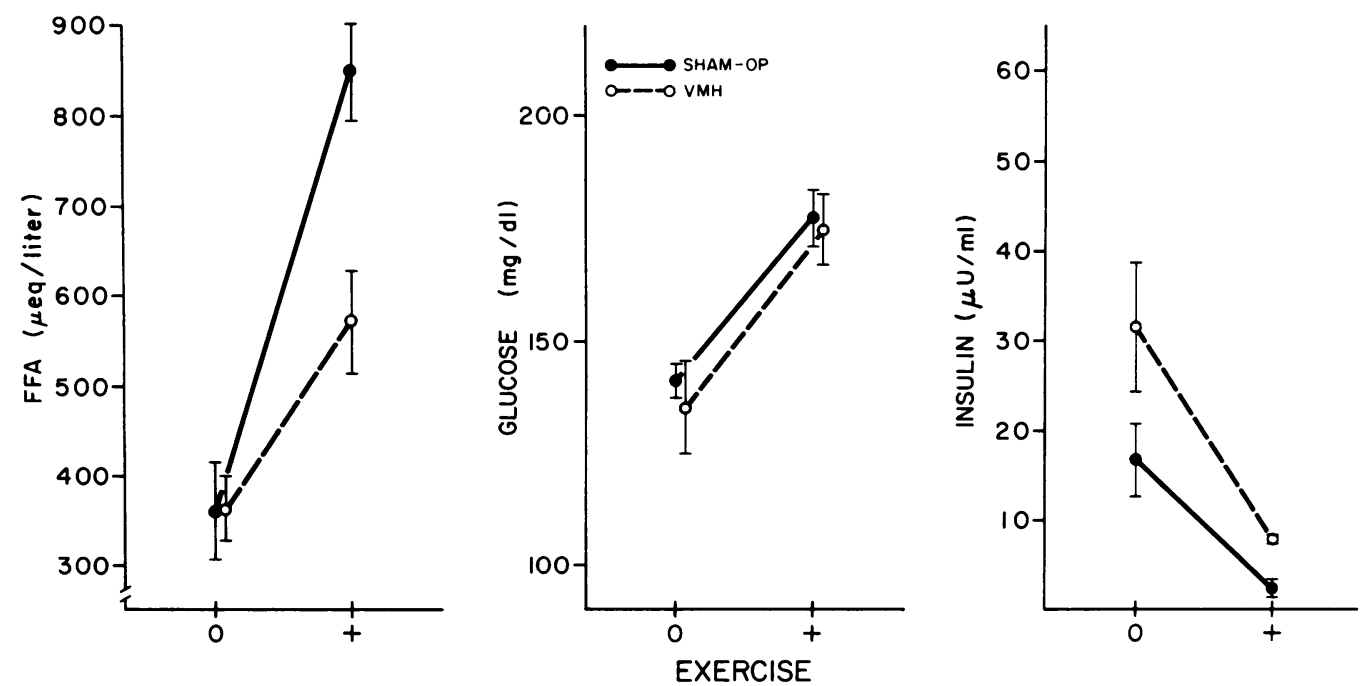

FIGURE 4 Effects of exercise in control and VMH-lesioned rats. The rise in FFA was significantly less in the VMH-lesioned rats than in the sham-operated animals, but unexercised animals from both groups showed comparable levels. The rise in glucose was similar and the fall in insulin, though starting from a higher level in the V.MH-lesioned animals, fell further but remained higher in the VMH-lesioned animals that were exercised.

animals (Table II). Glucose decreased significantly during the first $7 \mathrm{~h}$ of fasting but was not significantly different between the two groups at the beginning or end of the fast. The concentration of immunoreactive insulin fell with fasting but remained significantly higher in the VMH-lesioned rats at each time than at the corresponding times for the sham-operated animals (Table II).

\section{Experiment 6}

2-Deoxy-D-glucose. FFA rose more in the control animals treated with 2-deoxy-D-glucose than in the VMH-lesioned rats treated similarly (Table III). Adrenodemedullation did not modify the effect of 2-deoxy-D-glucose on FFA, but partially blocked the increase in serum glucose. Indeed, the apparent increase of $23 \mathrm{mg} / \mathrm{dl}$ in measured glucose could be accounted for by a 2-deoxy-D-glucose concentration of $50 \mathrm{mg} / \mathrm{dl}$. The levels of immunoreactive insulin were significantly higher in the lesioned rats, but there were no changes after injecting 2-deoxy-D-glucose in the adrenodemedullated rats. In contrast, there was a slight decrease in insulin the sham-operated adrenodemedullated animals injected with 2-deoxy-D-glucose.

\section{DISCUSSION}

The present experiments have examined the effects of VMH lesions on the mobilization of FFA by rats exposed to a variety of stresses. To interpret these experiments, it is essential to know that the response to exogenous norepinephrine was similar in VMHlesioned and in sham-operated controls. The first two

TABLE I

Effects of Exposure to Cold on VMH and Sham-Operated Rats

\begin{tabular}{|c|c|c|c|c|c|c|}
\hline & \multicolumn{2}{|c|}{ VMH-lesioned rats } & \multirow[b]{2}{*}{$P^{*}$} & \multicolumn{2}{|c|}{ Sham-operated rats } & \multirow[b]{2}{*}{$P^{*}$} \\
\hline & No cold & Cold & & No cold & Cold & \\
\hline No. of animals & 8 & 8 & & 7 & 7 & \\
\hline Body weight & $294 \pm 4 \ddagger$ & $290 \pm 3$ & & $292 \pm 3$ & $292 \pm 3$ & \\
\hline Glucose, $m g / d l$ & $135 \pm 6$ & $121 \pm 1$ & $<0.05$ & $137 \pm 3$ & $126 \pm 4$ & NS \\
\hline FFA, req/liter & $401 \pm 41$ & $515 \pm 30$ & $<0.05$ & $414 \pm 16$ & $626 \pm 24$ & $<0.001$ \\
\hline Glycerol, $\mu \mathrm{mol} / \mathrm{ml}$ & $0.24 \pm 0.02$ & $0.29 \pm 0.01$ & $<0.05$ & $0.25 \pm 0.01$ & $0.37 \pm 0.02$ & $<0.001$ \\
\hline Immunoreactive insulin, $\mu U / m l$ & $47.9 \pm 13.2$ & $46.7 \pm 6.9$ & NS & $24.3 \pm 2.2$ & $22.5 \pm 3.2$ & NS \\
\hline
\end{tabular}

* Comparison of no cold vs. cold.

$\$$ Mean \pm SEM for eight VMH-lesioned or seven sham-operated rats per group. 
TABLE II

Effects of Fasting on VMH and Sham-Operated Rats

\begin{tabular}{|c|c|c|c|c|c|c|c|}
\hline & \multicolumn{3}{|c|}{ VMH-lesioned rats } & \multicolumn{3}{|c|}{ Sham-operated rats } & \multirow[b]{2}{*}{$P^{*}$} \\
\hline & $0 \mathrm{~h}$ & $8 \mathrm{~h}$ & $24 \mathrm{~h}$ & () $\mathrm{h}$ & $8 \mathrm{~h}$ & $24 \mathrm{~h}$ & \\
\hline No. of animals & 8 & 8 & 8 & 8 & 8 & 8 & \\
\hline Body weight & $244 \pm 4 \ddagger$ & $245 \pm 3$ & $244 \pm 4$ & $249 \pm 4$ & $249 \pm 4$ & $250 \pm 6$ & \\
\hline Glucose, $m g / d l$ & $136 \pm 3$ & $126 \pm 2$ & $108 \pm 2$ & $140 \pm 5$ & $116 \pm 2$ & $106 \pm 2$ & NS \\
\hline$P \S$ & \multicolumn{3}{|c|}{$<0.05$} & \multicolumn{3}{|c|}{$<0.01$} & \\
\hline FFA, req/liter & $366 \pm 50$ & $631 \pm 51$ & $916 \pm 26$ & $351 \pm 21$ & $774 \pm 44$ & $1,106 \pm 45$ & $<0.05$ \\
\hline$P \S$ & \multicolumn{3}{|c|}{$<0.01 \quad<0.01$} & \multicolumn{2}{|c|}{$<0.001$} & & \\
\hline Glycerol, $\mu \mathrm{mol} / \mathrm{ml}$ & $0.20 \pm 0.02$ & $0.32 \pm 0.02$ & $0.33 \pm 0.02$ & $0.20 \pm 0.01$ & $0.32 \pm 0.02$ & $0.41 \pm 0.02$ & $<0.05$ \\
\hline$P \S$ & \multicolumn{3}{|c|}{$<0.01 \quad<0 .(0)$} & \multicolumn{3}{|c|}{$<0.01 \quad<0.01$} & \\
\hline $\begin{array}{l}\text { Immunoreactive insulin, } \mu U / m l \\
P \S\end{array}$ & \multicolumn{3}{|c|}{$<0.01 \quad<0.01$} & $\begin{array}{r}22.7 \pm 3.1 \\
<0\end{array}$ & $1^{5.85 \pm 1.25}<$ & 01 & $\mathrm{NS}$ \\
\hline
\end{tabular}

* Comparison of values between VMH-lesioned and sham-operated animals after $24 \mathrm{~h}$ of fasting.

$\$$ Mean \pm SEM for eight animals.

$\$$ Comparison of 8 and $24 \mathrm{~h}$ of fasting with fed animals.

experiments were designed to make this comparison by measuring the time-course and dose response to exogenous norepinephrine. The rise in glycerol as a measure of lipolysis was the same (dose-response curve) or greater (time-course) in the VMH-lesioned animals than in controls. Both the log-dose response to the injection of norepinephrine and the time-course of response showed a smaller rise in FFA than glycerol in the lesioned rats. This smaller rise in FFA relative to glycerol suggests the possibility that reesterification was occurring more rapidly in the adipose tissue of the lesioned animals. Inasmuch as reesterification requires a continuous supply of glycerol-3-phosphate generated from glucose, this result might be expected if the higher levels of insulin were biologically active. The smaller rise in FFA relative to glycerol might also reflect differences in the rate of peripheral removal of these two substances. The available data indicate that removal of both glycerol and FFA is a linear function of their plasma concentration $(16,17)$. It seems unlikely, therefore, that the parallel rise in glycerol and FFA can reflect anything but enhanced lipolysis under the conditions of these experiments. This implies that the myriad of factors that might have modified the response to exogenous norepinephrine did not affect the model used here. We were particularly concerned with the possibility that the hyperinsulinemia that characterizes the VMH-lesioned syndrome $(4,5)$ might interfere with

TABLE III

Effect of 2-Deoxy-D-Glucose in Intact and Adrenodemedullated Rats with Sham-Operations or VMH-Lesions*

\begin{tabular}{|c|c|c|c|c|c|c|c|c|c|}
\hline \multirow[b]{2}{*}{ Adrenodemedullation } & \multicolumn{4}{|c|}{ Sham lesions } & \multicolumn{4}{|c|}{ VMH lesions } & \multirow[b]{2}{*}{$P \downarrow$} \\
\hline & 0 & 0 & + & + & () & () & + & + & \\
\hline 2-Deoxy-D-glucose, & & & & & & & & & \\
\hline $560 \mathrm{mg} / \mathrm{kg}$ & 0 & + & 0 & + & 0 & + & 0 & + & \\
\hline Body weight, $g$ & $266 \pm 4$ & $269 \pm 4$ & $269 \pm 5$ & $269 \pm 4$ & $269 \pm 3$ & $219 \pm 2$ & $269 \pm 2$ & $270 \pm 2$ & \\
\hline Glucose, mg/dl & $144 \pm 4$ & $289 \pm 20$ & $140 \pm 2$ & $163 \pm 9$ & $132 \pm 2$ & $282 \pm 16$ & $126 \pm 2.0$ & $149 \pm 3.8$ & $\mathrm{NS}$ \\
\hline$P \S$ & \multicolumn{2}{|c|}{$<0.001$} & \multicolumn{2}{|c|}{$<0.05$} & \multicolumn{2}{|c|}{$<0.001$} & \multicolumn{2}{|c|}{$<0.01$} & \\
\hline FFA, $\mu e q /$ liter & $355 \pm 20$ & $606 \pm 77$ & $309 \pm 28$ & $592 \pm 52$ & $316 \pm 29$ & $416 \pm 53$ & $318 \pm 20$ & $404 \pm 67$ & $<0.05$ \\
\hline$P \S$ & \multicolumn{2}{|c|}{$<0.05$} & \multicolumn{2}{|c|}{$<0.01$} & \multicolumn{2}{|c|}{ NS } & \multicolumn{2}{|c|}{ NS } & \\
\hline Glycerol, $\mu \mathrm{mol} / \mathrm{ml}$ & $0.19 \pm 0.01$ & $0.26 \pm 0.01$ & $0.21 \pm 0.02$ & $0.27 \pm 0.01$ & $0.18 \pm 0.01$ & $0.22 \pm 0.01$ & $0.16 \pm 0.01$ & $0.21 \pm 0.02$ & $<0.05$ \\
\hline$P \S$ & \multicolumn{2}{|c|}{$<0.01$} & \multicolumn{2}{|c|}{$<0.05$} & \multicolumn{2}{|c|}{$<0.0 .5$} & \multicolumn{2}{|c|}{$=0.05$} & \\
\hline $\begin{array}{l}\text { Immunoreactive } \\
\text { insulin, } \mu U / m l \\
P \S\end{array}$ & $30.4 \pm 2.8$ & $22.6 \pm 2.1$ & $20.3 \pm 3.0$ & $21.4 \pm 4.2$ & $61.4 \pm 7.5$ & $46.1 \pm 10.6$ & $54.8 \pm 10.4$ & $54.0 \pm 7.0$ & \\
\hline
\end{tabular}

* Rats were adrenodemedullated $8 \mathrm{wk}$ before the hypothalamic lesions.

1 Comparison of 2-deoxy-D-glucose treated animals in sham-operated and VMH-lesioned groups.

${ }^{-}$Mean \pm SEM for 10 animals per group.

$\$$ Effect of treatment with 2-deoxy-D-glucose. 
the lipolytic effect of norepinephrine, because insulin is an antilipolytic agent for catecholamine-induced lipolysis (18). Hyperinsulinemia was present in the VMH-lesioned rats in all experiments even though body weights and food intake were similar to those in the sham-operated animals. This confirms data from other laboratories (19-21). An effect of the higher insulin levels on metabolism of adipose tissue may be reflected in the lower concentrations of FFA relative to glycerol in the first two experiments. The fact that the rise in glycerol was greater than the rise in FFA in response to log-dose increases in norepinephrine indicates, however, that the hyperinsulinemia of the VMH-lesioned rats was not inhibiting catecholamineinduced lipolysis in vivo. In the remaining studies, we have, therefore, used the changes in the serum concentrations of FFA and glycerol as an index of the response to endogenous norepinephrine released from the sympathetic nervous system.

Differences in the initial concentrations of glycerol and FFA between VMH-lesioned and intact rats would also have influenced the interpretation of our experiments. To select the most appropriate model, we compared the effect of stress in both ad lib. and pair-fed lesioned rats. When VMH-lesioned rats were allowed to eat ad lib., the concentrations of FFA and glycerol were significantly lower. Pair-feeding for the latter half of the experiment (Fig. 1), however, produced animals with the same final body weight and similar concentrations of glycerol and FFA. We thus used pair-fed animals for the remaining studies.

With all of the stressful experimental manipulations employed in this study, the rise of FFA and glycerol was significantly less in the VMH-lesioned animals than in the sham-operated controls. This supports the concept that the VMH lesion interferes with mobilization of FFA during stress in the experimental syndrome of hypothalamic obesity. A similar conclusion has been suggested previously by Inoue et al. (9). In this earlier study, it was observed that VMH lesions were associated with a rise in insulin, a decline in serum glucagon, and a decrease in the weight of the submandibular salivary glands. These findings were interpreted to indicate decreased sympathetic activity after VMH injury. The present studies strengthen this hypothesis.

Physical exertion mobilized FFA, increased glucose, and significantly decreased insulin in both VMHlesioned and sham-operated animals. A rise in FFA and glucose and a fall in insulin have been noted previously by others (22-27). Luyckx et al. (28) showed that immunosympathectomy significantly reduced the rise in FFA and that adrenodemedullation did not affect it, indicating the importance of the sympathetic nervous system in the mobilization of fatty acids during exercise. Our studies are consistent with this interpreta- tion and show, in addition, that the magnitude of the response in the VMH-lesioned animals is smaller than in the intact controls.

The effect of cold exposure was different in two respects from that of forced exercise. Although the rise in FFA in the VMH-lesioned animals was significantly less than in the controls, neither glucose nor insulin changed during $60 \mathrm{~min}$ in the cold. This implies that the magnitude of cold exposure as a stress was less than that of forced exercise or, alternatively, that the mobilization of FFA in the cold was due to release of epinephrine from the adrenal medulla. Maickel et al. (29) have examined this latter possibility and found that removal of the adrenal medulla does not diminish the mobilization of FFA. We would thus conclude that cold was a less severe "stress" than forced exercise, and that it is modified by VMH-lesions.

Fasting is known to increase the concentration of FFA (29-32), and this is consistent with our findings. In addition to raising FFA, fasting also increased glycerol and reduced both insulin and glucose in all groups, but the effects were greater in the sham-operated animals than in those with VMH lesions.

The experiment with 2-deoxy-D-glucose is consistent with the observations of others $(33,34)$. The rise in FFA was significantly less than in the VMH-lesioned animals whether the adrenal medulla was present or not, implying that catecholamines from the adrenal medulla are not involved in this effect. Others have shown, however, that more extensive hypothalamic lesions, such as deafferention, completely block the rise of FFA (33). The rise in glucose, on the other hand, was abolished in the lesioned and intact animals in the absence of the adrenal medulla. This has been emphasized by previous studies showing loss of the hyperglycemic response to 2-deoxy-D-glucose in the absence of the adrenal medulla $(34,35)$. The VMH lesions per se, however, did not affect the rise in glucose. This suggests that the hyperglycemia and the mobilization of lipid are controlled by separate regions of the hypothalamus which act through different peripheral mechanisms.

The present experiments tested the hypothesis that VMH lesions might interfere with adrenergic control of FFA mobilization. They are consistent with this hypothesis and suggest that the ventromedial hypothalamus may modulate lipid storage and release in man (4) and animals (5). Modulation of lipid mobilization could have profound effects on storage of body fat. It has long been known that bilateral lesions of the ventromedial hypothalamus result in obesity $(4,5,36,37)$. Our understanding of the organization of the ventromedial hypothalamus has been extended by the anatomic observations of Ban $(6,7)$ and by the studies with electrical stimulation published by Frohman and Bernardis (38) and by Shimazu and his colleagues 
$(39-41)$. Ban $(6,7)$ has shown that the VMH nucleus is part of the anatomic organization of the sympathetic neural output from the hypothalamus. He divides the hypothalamus into medial and lateral parasympathetic zones separated by a medial sympathetic zone. The ventromedial region of the hypothalamus lies in this medial sympathetic zone. Stimulation of this region raises glucose and glucagon, and decreases insulin during the period of stimulation. It also raises growth hormone (42). Shimazu et al. (39-41) found an increase in glucose and have shown that stimulation of the ventromedial region of the hypothalamus can activate hepatic enzymes involved in glycogenolysis and gluconeogenesis. Electrical stimulation of this region in the rabbit brain can also increase lipolysis (41). Our studies have extended this concept by showing that destruction of the ventromedial sympathetic region of the hypothalamus is followed by a reduction in the mobilization in FFA by stimuli that involve the sympathetic nervous system. These studies taken together suggest that the ventromedial hypothalamus may act as a modulator of peripheral efferent adrenergic activity, particularly that involved with regulating adipose tissue mass.

Reduced activity of the sympathetic nervous system would also be expected to increase the concentration of insulin, to decrease the concentration of glucagon, and to reduce lipolysis, all of which have been observed in the syndrome of hypothalamic obesity (9). Such a sequence of events would favor the storage of triglycerides and thus the development of obesity. These observations of decreased sympathetic activity in the experimental animals provide a basis for reevaluating those patients who have the syndrome of hypothalamic obesity and suggest that sympathomimetic agents may be of value in treatment of these individuals.

\section{ACKNOWLEDGMENTS}

The technical help of Ms. M. Lee and the secretarial help of Ms. J. Martinez are gratefully acknowledged.

This work was supported in part by National Institutes of Health grants AM 15165 and A.M 18186.

\section{REFERENCES}

1. Bray, G. A., and D. A. York. 1971. Genetically transmitted obesity in rodents. Physiol. Rev. 51: 598-646.

2. Bray, G. A. 1976. The Obese Patient. In Major Problems in Internal Medicine. W. B. Saunders Company, Philadelphia. 9: $1-450$.

3. Schemmel, R., O. Mickelsen, and J. L. Gill. 1970. Dietary obesity in rats: body weight and body fat accretion in seven strains of rats. J. Nutr. 100: 1041-1048.

4. Bernardis, L. L., and J. K. Goldman. 1976. Origin of endocrine-metabolic changes in the weanling rat ventromedial syndrome. J. Neurosci. Res. 2: 91-116.

5. Bray, G. A., and T. F. Gallagher, Jr. 1975. Manifestations of hypothalamic obesity in man: a comprehensive investigation of eight patients and a review of the literature. Medicine (Baltimore). 54: 301-330.

6. Ban, T. 1966. The septo-preoptico-hypothalanic system and its autonomic function. Prog. Brain Res. 21 A: 1-43.

7. Ban, T. 1975. Fiber connections in the hypothalamus and some autonomic functions. Pharmacol. Biochem. Behat. 3: $3-13$.

8. Frohman, L. A. 1978. The central nervous system and metabolic regulation. Adv. Mod. Nutr. In press.

9. Inoue, S., L. A. Campfield, and G. A. Bray. 1977. Comparison of metabolic alterations in hypothalamic and high fat diet-induced obesity. Am. J. Physiol. 233: R162R168.

10. Inoue, S., and G. A. Bray. 1977. The effects of subdiaphragmatic vagotomy in rats with ventromedial hypothalamic obesity. Endocrinology. 100: 108-114.

11. Bray, G. A. 1964. Studies on the relation of thyroid hormone and catecholamines.J. Clin. Invest. 43: 28.5-294

12. Federspil, G., P. Lefebvre, and A. Luyckx. 1969. Effets d'un exercice musculaire continu (nage forcée) sur la glicémie et le taux plasmatique des acides gras libres, de l'insuline et de la corticosterone chez le rat. Arch. Int. Physiol. Biochim. 77: 778-786.

13. Dole, V. P. 1956. 1956. A relation between non-esterified fatty acids in plasma and the metabolism of glucose. J. Clin. Invest. 35: 150-154.

14. Davidson, M. B., and R. Karjala. 1970. Simplified fluorometric method for the determination of plasma glycerol. J. Lipid Res. 11: 609-612.

15. Morgan, C. R., and A. Lazarow. 1963. Inmunoassay of insulin: two antibody systems. Plasma insulin levels of normal subdiabetic and diabetic rats. Diabetes. 12 : 115-126.

16. Armstrong, D. T., R. Steele, N. Altszuler, A. Dunn, J. S. Bishop, and R. C. DeBodo. 1961. Regulation of plasma free fatty acid turnover. Am. J. Physiol. 201: 9-15.

17. Shaw, W. A. S., T. B. Issekutz, and B. Issekutz, Jr. 1975. Interrelationship of FFA and glycerol turnovers in resting and exercising dogs. J. Appl. Physiol. 39: 30-36.

18. Jungas, R. L., and E. G. Ball. 1963. Studies on the metabolism of adipose tissue. XII. The effects of insulin and epinephrine on free fatty acid and glycerol production in the presence and absence of glucose. Biochemistry. 2: 383-388.

19. Han, P. W., and L. A. Frohman. 1970. Hyperinsulinemia in tube-fed hypophysectomized rats bearing hypothalamic lesions. Am. J. Physiol. 219: 1632-1636.

20. Hustvedt, B. E., and A. L $\emptyset$ v $\varnothing$. 1972. Correlation between hyperinsulinemia and hyperphagia in weanling rats with ventromedial hypothalamic lesion. Acta Physiol. Scand. 84: 29-33.

21. Goldman, J. K., L. L. Bernardis, and L. A. Frohman. 1974 Food intake in hypothalamic obesity. Am. J. Physiol. 227: $88-91$.

22. Koivisto, V. A., H. K. Åkerblom, and M. K. Kiviluoto. 1974. Metabolic and hormonal effects of exercise in the severely streptozotocin-diabetic rat. Diabetologia. 10: 329-335.

23. Lefèbvre, P. J., A. S. Luyckx, and G. Federspil. 1972. Muscular exercise and pancreatic function in rats. Isr. J. Med. Sci. 8: 390-398.

24. Luyckx, A. S., and P. J. Lefèbvre. 1974. Mechanisms involved in the exercise-induced increase in glucagon secretion in rats. Diabetes. 23: 81-93.

25. Federspil, G., G. Udeschini, C. De Palo, and N. Sicolo. 1975. Role of growth hormone in lipid mobilization stimulated by prolonged muscular exercise in rat. Horm. Metab. Res. 7: 484-488. 
26. Boninsegna, A., G. Federspil, and C. De Palo. 1974. The effect of muscular exercise on free fatty acids, acetoacetate and 3-hydroxybutyrate blood levels. Horm. Metab. Res. 6: 488-491.

27. Gollnick, P. D. 1967. Exercise, adrenergic blockage and free fatty acid mobilization. Am. J. Physiol. 213: 734-738.

28. Luyckx, A. S., A. Dresse, A. Cession-Fossion, and P. J. Lefèbvre. 1975. Catecholamines and exercise-induced glucagon and fatty acid mobilization in the rat. Am. J. Physiol. 229: 376-383.

29. Maickel, R., H. Sussman, K. Yamada, and B. Brodie. 1963. Control of adipose tissue lipase activity by the sympathetic nervous system. Life Sci. 3: 210-214.

30. Balasse, E. 1968. Influence of norepinephrine, growth hormone, and fasting on FFA mobilization and glucose metabolism in lean and obese subjects. Diabetologia. 4: $20-25$.

31. Bray, G. A. 1966. Effects of reserpine on hepatic glycogen and plasma free fatty acids of thyroidectomizedadrenodemedullated rats. Proc. Soc. Exp. Biol. Med. 121: $330-335$.

32. Salvador, R. A., K. I. Solville, and J. J. Burns. 1965. Adrenergic mechanisms and lipid mobilization. Ann. N.Y. Acad. Sci. 131: 113-118.

3.3. Teixeira, V. L., J. Antunes-Rodrigues, and R. H. Migliorini. 1973. Evidence for centers in the central nervous system that selectively regulate fat mobilization in the rat. J. Lipid Res. 14: 672-677.

34. Brown, J., and H. L. Bachrach. 1959. Effects of 2-deoxyglucose on blood glucose levels in the rat. Proc. Soc. Exp. Biol. Med. 100: 641-643.

35. Frohman, L. A., E. E. Muller, and D. Cocchi. 1973. Central nervous system mediated inhibition of insulin secretion die to 2-deoxyglucose. Horm. Metab. Res. 5: 21-26.

36. Stevenson, J. A. F. 1969. Neural control of food and water intake. In The Hypothalamus. W. Haymaker, E. Anderson, and W. J. H. Nauter, editors. Charles C. Thomas Publisher, Sprinfield, Ill. 524-621.

37. Brobeck, J. R. 1946. Mechanism of the development of obesity in animals with hypothalamic obesity. Physiol. Rev. 26: 541-559.

38. Frohman, L. A., and L. L. Bernardis. 1971. Effect of hypothalamic stimulation on plasma glucose, insulin, and glucagon levels. Am. J. Physiol. 221: 1596-1603.

39. Shimazu, T., and A. Amakawa. 1968. Regulation of glycogen metabolism in liver by the autonomic nervous system. II. Neuronal control of glycogenolytic enzymes. Biochim. Biophys. Acta. 165: 335-348.

40. Shimazu, T., and S. Ogasawara. 1975. Effects of hypothalamic stimulation on gluconeogenesis and glycolysis in rat liver. Am. J. Physiol. 228: 1787-1793.

41. Kumon, A., A. Takahashi, T. Hara, and T. Shimazu. 1976. Mechanism of lipolysis induced by electrical stimulation of the hypothalamus in the rabbit. J. Lipid Res. 17: $551-5.58$.

42. Frohman, L. A., and L. L. Bernardis. 1968. Growth hormone and insulin levels in weanling rats with ventromedial hypothalamic lesions. Endocrinology. 82: $1125-1132$ 